\title{
'Onwe': An Inquiry into the Igbo Concept of the Self
}

\author{
Chuka A. Okoye \\ doi: http://dx.doi.org/10.4314/og.v8i1.4
}

I

Our view is that the Igbo concept of the self forms an integral part of their world-view and culture. The concept of the 'self' generates, till date, a controversial reaction especially among metaphysicists as to what makes up the self and how its nature affects the Universe. Theorists have found it easier to explain that the self is a phenomenal entity which reacts towards its noumenal part. However, the process of their (Phenomenal and noumenal) interaction remained a point of divergence. The above problem, though essential to this essay may not be the very focal point especially as the view of the 'self' for an Igbo (African) may be somewhat disinterested in the process of interaction.

The self is seen not only as that whish is personal but also a being with others. This immediately points towards the fact that the very understanding of the self is the starting point of any inquiry into any people's culture and the reason for their actions. Suffice it to say that the knowledge of the world can never be possible without the knowledge of the self. The Cartesian cogito ergo sum, the kantian corpernican revolution, Husserl's phenomenology and Berkeley's immateriality in which the self became the centre and the beginning of every inquiry into nature prove this fact. One may, therefore, not be surprised at the way the Igbo (African) man views his world and how he reacts to it, having been made to understand the Igbo (African) concept of the self.

In the course of this essay, I shall look at the general Igbo cosmology which serves as the very foundation of their understanding of the self. This will eventually lead us to the very understanding of the self as conceived by the Igbo people. I shall afterwards be examining the effect this very understanding has on the life of the Igbo in general. At the end of this, I shall make an evaluation of the African concept of the self with my recommendations. 


\section{II}

The African (Igbo) concept of the self cannot be successfully discussed without reference to their cosmology. The Igbo cosmology, I must point out immediately, are corporate beliefs. These beliefs are not unanimously accepted by all Igbo people but are shared by most of the Igbo communities.

The Igbo see the world from the lens of myths, taboos, proverbs etc. this is to say that the beingness of man in the world and his place in it together with his hopes, and end are explainable through the above mentioned media. Nwoga emphasized that

The Mythology of a Community contains those stories which represent the underlying truths behind the life of the community.... The Mythical stories and cosmogonic tales of the Igbo are good sources from which we can distill the Igbo conception of Ultimate causalities, their beliefs systems as they relate to deifies and the relationship between man and the other forces ${ }^{1}$.

Through mythologies, the Igbo man explains the world and the raison d'etre of the thing therein. However this is not limited to the Igbos as other human groups like the Jews, Babylonians, and other Africans such as the Akans, Yorubas etc have their own mythological explanation about their world. The bottom line of these various myths is that from time immemorial, the earth and the heavens have got a basic interaction which leads understandably to the nature of the world and even the division of the 'self'.

The Igbo divided the universe into three categories, namely: The Eluigwe-The Sky; The Ala Мтио- The Spirit world; The Ala mmadu - The land of the living. The Eluigwe is seen as the abode of the Chi Ukwu-the Supreme deity. It is the Chi Ukwu in the Sky that diviners, medicine men and the elders first present the kolanut before breaking it ${ }^{2}$. The Igbo believes that there is no direct touch between this supreme deity-chi $u k w u$ and the human beings. Any kind of interaction, communication and/ or otherwise should be done through the intermediaries who are like His ambassadors. These 
intermediaries include: The ancestors, the other smaller deities- alusi and personal chi of everybody.

The affairs of the land of the living are further controlled by this supreme deity. This task of sustenance and control earned him another name Olisa Buluwa or Osebuluwa- the sustainer. Apart from this task of sustenance He created the world thus this name-Chineke. All offerings go to Him through his ambassadors and He reaches back to the Universe, according to the Igbos through the same media.

On the second world-the ani mmиo, the Igbos believe that it is here that numerous spirit-beings reside. The human Spirits on Sojourn back to the earth and from the earth awaiting their return inhabit this universe. These spirits especially those of the ancestors are believed by the Igbos to play active roles in the earthly activities. Little wonder that every year a ceremony is organized among the Igbos to commemorate their ancestors who are believed to re-unite with them and share their communion. Much respect is given to the ancestors and care, further, is taken by the living to make good their lives as to enable them join the ancestors in this spirit world when they depart from their bodily existence.

The third world is the earth-ani mmadu. This is a plain of phenomenal realities. It is a world which is inhabited essentially by all animate things-man, animal, plants and minerals. The earth however is not, according to the Igbo belief limited to only the physical men. Spirits are equally encountered here especially spirits that are in transit or even some who come to leave very relevant piece of information with the living in the ani-mmadu. The encounter with these spirit-men is not usually for the general public. Instead deeply spiritual men or trained and gifted people may be opportuned to have this encounter. It is within this plain that the forces of life seem to be most active. Since the higher beings in the other worlds need not enhance their forces, they help the beings on earth to enhance or even enfeeble their forces each depending on the act of the being in question.

One may not be thrown off balance, sequel to this Igbo cosmology, trying to understand the African (Igbo) Concept of the self. The self, evidently, is understood better in the Igbo context when reference is made to it in relation to the various worlds it 
interacts with. No doubt, the world as understood by the Igbo (African) encompasses both the physical and the spiritual entities. This suggests, outright, the concept of the self not just as a material entity, following the principal of metabolism or just a mind following the principle of mentalism. The self is an entity made up of both the physical and the non-physical substances. It is the combination of the both the physical and non physical parts of the self that account for the life, action and even the destiny of the 'self'. The self, from the above, is thus understood as both an ethical and an existential concept.

The 'self' according to the Igbo understanding is categorized into three parts but not automatically in direct correlation with the three worlds discussed above but at the same time not estranged to them. The 'self' being an entity faced with destiny has everything about it centered on its nature and has it own environment explainable through it. We thus see the three categorizations of the self as follows: The Soul - Mkpuruobi; The Spirit- Мтио; The Body-Aru

The trio above constitutes what we call the 'onwe'-self in African (Igbo) thought.

The Mkpuruobi, according to the Igbo thought system forms the innermost self. That is to say, the very essence of the individual person is the 'Mkpuruobi'-soul. The unit of an individual's life is on the Mkpuruobi. No doubt even the Christians had borrowed the word but still use it as what exactly it implies-the life giving part of the 'self'-onwe on this part of Onwe lies the very destiny of the self. The Mkpuruobi represents the spark of the Chi Ukwu in the self. Thus to speak of the self as an ethical concept makes reference to this part of it which by its nature drags the self towards the right channel of authentic existence.

This idea of the Mkpuruobi appears to have a Christian undertone. From the explanation of the Mkpuruobi as the very unit of the human life or life of the self, one quickly concludes that the absence of the Mkpuruobi means the death of the self. This evidently suggests a pure Christian teaching in which the catholic catechism teaches that our resemblance of God is in our soul and that the soul gets back to Him after leaving the body to the dust from where it came. 
The concept of Mkpuruobi as being used in the contemporary African belief system can be said to have a judaeo-christian perspective. Ogugua denied the existence of Mkpuruobi in the traditional Igbo Concept of personhood. He however contended that the word Mmuo rather suffices for both the concept of the Mmuo and Mkpuruobi respectively. The contention of Ogugua is understood. Nevertheless, despite the fact that the Mkpuruobi seems to open the way to the direct interaction of the self with God, it may not hold for the Igbo understanding of self. Benedict O. Eboh to this stated that

The Igbos do not specifically identify the seat of the human soul in man's body... the eating of the (anatomical) heart is one of the palpable Singular signs and so they regard it as a principle of life. it is not however, considered that 'Seat' of the soul as such, for although the heart is so closely associated with life, it is not believed to leave the body at death $^{3}$.

At this juncture, we may be poised to inquire more into this idea of the non-physical part of the self through its roles which we could be delineated as physical, the semi-physical (what Aristotle referred to as a rarefied matter) and the metaphysical parts of the self.

Nevertheless, following the western philosophy, the Мтио may not readily be endowed with some faculties which the Mkpuruobi is endowed with. According to the western philosophy, the soul possesses the capacity of existence. This may give some support to the Igbo belief in the soul as a matter which is rarefied. The soul is not physical hence it defies the spatio-temporal laws, which are mechanical and physical. It is this semi-physical state of the Mkpuruobi that renders it possible to be beheld by some physical men who are trained for this.

In The Theory of Igbo Immaterialism, Ike Nwankwo stated that the concept of the immaterial part of the human person bothers much on disciplinary and dialectical differenciation ${ }^{4}$. Nwakwo emphasized that what philosophy may choose to call the mind may be referred to 
differently by the psychologists. The psychologists' concept of the soul has generated a different problem to them from the philosopher who attempts to sort out the interaction problem between the mind and the body.

Furthermore, Nwankwo stressed that dialect is a major substance in the interpretation of the immaterial part of the person ${ }^{5}$. This explanation by Nwankwo no doubt is correct. This idea was supported by Bernard Williams. For Williams, it is clear that language has a lot of roles to play in the understanding of things. Williams Writes

Language forms the very base of understanding of ideas. One therefore sees that it is an important point that in Descartes' usage the Latin verb cogitare and the French verb penser... have a wider significance than the English think and thought. In English such terms are specially connected with ratiocinative or cognitive process ${ }^{6}$.

From the above, it is clear that Williams employed the Cartesian linguistic dilemma to explain the how much role the dialect can play in the interpretation of existential things. This was the same point which Nwankwo tried to defend in his second thesis.

Nwankwo explained that the terms Mkpuru-seed and obi-chest refers to the heart which is a seed being protected by the chest and not the non material entity called thee soul. With this, he removed every immaterial quality from the mkpuruobi while extending the horizon of the Мтио to still connote what some people may call mkpuruobi. For Nwankwo, the division of the immaterial aspect of the 'onwe' is limited to just the mmио. Nwankwo appears to be more direct in the general concept of the self. No doubt if we must attempt to fix up everything in the line of the contemporary (seeming hybrid) tradition of the Igbo people, we will be guilty of reductionism.

However, Nwankwo's extension of the 'Мтио' connotation may not really go entirely for me. I am compelled to raise the issue of consciousness here. Consciousness evidently expresses the complete man. One's own environment and personality including the very awareness of one's actions are made explainable through 
the consciousness. At the state of consciousness, the mind is aware of itself and the world. Thus, one is said to be fully aware of all his actions and thus has the full consent of the will. This is quite different from the state of subliminal consciousness in which the self is not aware of what one does or what influences one's actions. However, the Freudian psychoanalysis paints a more distinct picture of consciousness. He delineated three parts of the conscious mind the id which, according to him, is the part in which innate instinctive impulses and primary processes are manifest, super-ego which is the part of the mind that acts as a self-critical conscience and finally the ego which mediates this conscious super-ego and the unconscious id. This ego is that which gives one the sense of personal identity otherwise the sense of the sense of self. This consciousness ego in Freud is what the Igbos call 'ako na uche'- the conscious sense.

When one does not have an 'ako na uche' the person is said to be devoid of the sense of good judgment which just limits him to mere desire of self gratification. When this part of the 'self' -'onwe' is merged with the super-ego, a part which is easiest described as the conscience, it leads to a balance in personality-the 'ego'. The ego does not just act with the duo of $1 \mathrm{~d}$ and super-ego without full consciousness. For one to be classified as a full person he must be conscious and this consciousness is not and can never be solely an act of the 'mmио' so limited in definition.

Explaining 'ттио'- spirit, it is used generically to refer to all unperceivable mystical beings and forces ${ }^{7}$. It is from this understanding that Locke may be said to be right in making reference to the self as an activity. Thus explanation of Мтио does not really show forth any direct relationship with the physical states. If we go by this definition, we may likely end up in Rene Descartes' dilemma, a situation which he found himself by his substantial differentiation of the mind and body.

The Мтио I believe, if Nwankwo's view of dualism would be acceptable, must be extended to the sub-physical state in which the mind or spirit as the case may be takes up as an addition to the Metaphysical function, the sub-physical functions. Danquah may likely share this view as he writes about the Akan people saying that the mтио-spirit is the bearer of conscious experiences, the unconscious and subliminal consciousness. The Igbo believe that 
during the dream, the spirit also moves around and thus believe that dreams mirror reality come what may.

If one, for instance, dreams of masquerades, the dreamer feels that the spirits of the ancestors are at works. This view despite the influence of the Christianity still runs in the blood of the Igbo man. The spirit-man goes out during dreams, interacts with a lot of things. This is still partly true with the psychological explanation of dreams as a play of the subliminal consciousness. The dreamer operates on the subliminal conscious during the dream. One with this does not find it hard to explain why one dreams and acts out what he dreams in the sleeping state. The physical state evidently is not conscious at the state of dreaming. Thus the mmиo takes over from the activity of the 'aru'-body.

We can easily conclude here that the mmuo- spirit which transcends, which even understands and re incarnates is conscious. This will naturally give to the ттио also the faculty of reason'uche'. If we go by this, then the idea of Mkpuruobi which performs these functions as I explained earlier could be said to mean almost the same thing with the mmиo as regards their nature and the functions they perform. So with this they could be said to be the same.

The above conclusion was deliberately limited to the nature and functions. In usage, one may see something a bit different. The nature of Igbo language makes it very dicey to conclude that the mmuo and mkpuruobi are one and the same thing. The mmuo is often used wider than the mkpuruobi. In Igbo language, one could be found using ттио as vital force. To be sure, vital force according to

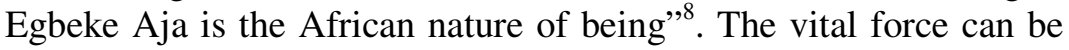
enfeebled or enhanced. This force here in question could suffice for ттио according to the Igbo. Sequel to this, we can hear an Igbo person speaking of his enhanced force in these words: Мтио $\mathrm{m}$ gbalitere elu. My Spirit is enhanced. Conversely, the Igbo can also say: Мтио m agbatua ani- my spirit has been enfeebled.

The ттио further can be used as morale in the Igbo thought. This usage proves further that the mmиo encompasses every spiritual and sub-physical action as argued above. If one is demoralized, one often finds the person saying egbuola ттио $\mathrm{m}$ - my spirit has been killed. There may be some difficulty here of trying to delimit what 
ттио stands for in the Igbo metaphysical thought nevertheless, we may state that the activities of mmиo cuts across those of Mkpuruobi thus rendering the seeming difference as a problem of dialect in principle. Despite the very important place given to the ттио in the explanation of the self, the 'Onwe'-self is not limited to merely a spiritual reality. Referring to 'Onwe $m$ '- myself, I phenomenally point towards not the ттио but to another substance-Ahu (body) which is palpable and visible.

The theory of materialism against mentalism believes that the self /person is not something that has, possesses, utilizes, or occupies the body. Instead, the self as the mind and its body are one and the same thing. The materialist may be inclined to emphasize more the body -aru over the mind/spirit-mmиo. They believe that it is the body that actually makes the self referent. However, the Igbo may take a contrary position believing that the mтио contributes more to the self than the body. To say the least, the Igbos like Plato believe that is it in the nature of the тmио to rule the self thus the expressions like: Mmuo na-achim the spirits, which governs me.

Our understanding of the Igbo concept of the self so far suggest a dualistic not a tripartite concept of the self. Thus, a person is made up of two entities namely: the material the $a h u$ and the immaterialттио. The ahu constitutes the visible part of the self which is characterized by extension and palpability. The ahu-body in the Igbo concept of the self may not be as passive as the Descartes' res extensa: for the Igbo, the ahu plays an active role in the self. Whereas the ттио serves as the principle of performance, the ahu constitutes a ground for constant change, which makes the inquiry into the problem concerning the concept of the self possible.

The various parts of the body play very important role in the existential and metaphysical interpretation of the self. The Igbo people hold 'blood'-Obara in high regard especially as it refers to the explanation of the self. One, in the Igbo context is likely to point at blood as the major physical determining factor for the self. Nevertheless, the Obara here, we must understand has a deeper meaning than just blood. Blood is a very important factor in life. To say the least, blood gives life to the body. A body without blood or has its blood dysfunctional is often said to be sick or dead. This idea is not limited to the Igbo people. A person, in the orthodox medical 
system, for instance, is diagnosed of many sicknesses through his blood samples.

This crucial role of the blood to the human body may not be doubted as one of the reason why the Igbo people emphasize the blood in the explanation of the self. The blood ties the physical part of the self- $a h u$ to his consanguine and the society. When an individual is seen in the Igbo society, for example, one then tries to identify the 'Onwe' of the person who may have changed physically over time. Further inquiry may leave the seeker with an option of guessing who he encountered. To make this guess, one often asks: I bu onye be Okoye?- Are you from the Okoye's?. When the answer is on the affirmative as it most often happens the person exclaims again saying Obara anaghi atu asi- blood does not tell lies. The blood here has been used to explain the self-onwe of the seeming physically changed person.

Furthermore, the Onwe of the father (Primogenitor) is believed to impact much on the onwe of his descendants. Care must be taken here not to misunderstand the above statement which does not suggest that the self of the father is transferred to the children as the Akan people believe. For the Igbo People, there is instead a very close ontological tie between the onwe of the 'di-bu-uno' (Primogenitor) and the Onwe of his descendants. The actions of one is likely to be justified not exactly from the 'Onwe' of the individual alone but also linked to the 'onwe' of the family tree starting with their 'di-bu-uno'. It is therefore absurd to say in Igbo: A bu m naani onwe $m$ - I am myself alone. When one steals in Igbo culture or does any wrong, it-is traced back to the Onwe of their family di-bu-uno. One often says: Omume a di na Obara-this action runs in their blood. The same goes with positive actions, bravery, spirituality etc.

The blood from the above explains the self- onwe from the perspective of consanguinity. However, we cannot deny the fact that there is the possibility of one imbibing a character strange from the family tree. Here, the Igbo man would likely blame such an action on either Отити-learning or on the family tree of the mother of the child. This clearly reflects the Igbo concept of causality in which they believe that nothing happens without a cause. The action of every 'onwe' is influenced mainly by blood and less frequently by отити (learning). One may wonder, from the above Igbo 
understanding of the onwe, what the mmиo does since the actions of man seem to be guided much from the family blood. The ттиоspirit in the philosophical discipline and even in many cultural beliefs is said to play the major role of influencing the body towards certain actions that are not reflex. The problem generated here often leads to the problem of mind and body interaction. The Igbo belief in 'Obala' does not rule out entirely the mind/spirit's influence on the body, as we shall see shortly, but presents us a good understanding of how the ттио and $a h u$ influence each other.

\section{III}

The Igbo believe that the Ahu and Мтио constitute one whole called the self. This necessarily entails that the Igbo maintain a dualistic not really a tripartite conception of the self. For the Igbo people, the $a h u$ self is made up of two entities namely: the spiritual and the physical as in the Мтио and respectively. The Igbo people may not readily enter into much difficulty trying to explain the mind and body relationship and like I mentioned in the section 1 of this work, the problem of interactionism may surface but will not be at the center of discourse because the process of this interaction may not really matter for the Igbo man.

The Igbo speaks often, with reference to the mind and body relationship, as if the two are so close that they comprise one indivisible whole. The self for the Igbo man could be said to be a homogeneous entity. If we go by this, then we may encounter a little but serious problem of the possibility of disintegration of both entities after death. The Igbo believed that at death, the spirit-mmиo of the individual journeys on to the land of the ancestors. This is why during some burial ceremonies especially of the kings and influential people, some heads are cut and buried with the dead. These heads, it is believed, would be slaves to such kings in the land of ancestors. More to it, the funeral rites not duly performed is believed to deny the dead one the right into the ancestral universe thus often we find the Igbo people spending much to bury their dead.

From the above, we agree that the Igbo believe in life after death. This thesis may seem a contradiction maintaining the belief in the indivisible union of the Мтио and aru and the issue of life after death which is cyclical. This idea is nonetheless very difficult to 
reconcile but I think that the Igbo will be reluctant to split the actions of the mind and body or even to proffer limitations to their various activities. However, the Igbo may not dismiss the influence of the Мтио over the ahu. For example, the physical actions of a man are referred back to the activities of the Мтио in which it functions as the Uche as I brought out Previously in the section II of this work. To refresh our minds, I brought out the problem of the consciousness and emphasized 'Uche' as a very essential thing which the Mтио's function also connotes. The Uche being a part of Мтио, appear to play the role of the consciousness which the Igbo believe speaks to the body and makes it swing into action. The Igbo people often are found saying. Obu Ihe Uche gi gwara gi? Is that what your spirit directed (told) you? Or we can also hear people say: Gee Onwe gi nti-listen to your intuition. This shows that the activities of the body are mainly governed by the mmuo which tells the $a h u$ what to do at every point in time.

The ттио is not just a bundle of qualities as some thinkers believe. It is rather a spiritual entity not a bundle of perceptions as David Hume would say or merely activity as John Locke postulated. It is eternal just like the chi-ukwu (Supreme God) whose likelihood the mтио bears. But where does the mmиo live? This question has rattled many philosophers of the past. Plato in the ancient epoch of philosophy is most likely to fit into Igbo understanding of the abode of the ттио unlike the later philosophers after him. Descartes for instance systematically packaged the soul in the pineal gland without much justification. Leibniz would rather attempt at making it more independent of any abode especially the body. Nevertheless the Igbo people like Plato will accept that the mmиo inhabits the body in its immateriality. The mтио is so glued to the body that they are inseparable until death. Hence the saying: Ihe di n'ime mmadu mere ya ihe Obu- that which is inside one makes one who he is.

The spirit actions are necessarily effected on the body and the bodily actions equally is believed to have a spiritual effect. This causal interaction suffuses almost all the cultural beliefs of the Igbo people. Ibeh on this commented that

The general belief of the Igbos of Nigeria are Primarily based on their understanding of their 
world and the interaction of things there in as caused...The world of man and the world of the spiritual (ancestral) world are in constant causal relationship that the activity of one affects the other. ${ }^{9}$

The Igbos are likely to connect the misfortunes encountered in the physical with the (metaphysical) spiritual and vice verse. When one sets out to perform some acts and suddenly begins to feel jittery or down cast or even experiences a strong set back, the cause is usually traced back to the persons spirit mтио. Thus we say: ттио $\mathrm{m}$ anabataghi ya (my spirit rejects this). Furthermore, spiritual uncleanness could also be attributed as a major cause of physical ailment and so long as the spirit remains unclean, the body may not be given an opportunity of good health.

On the other hand, one's physical state in the Igbo understanding, gives a great insight to the states of one's spirit. If a man's action suggests that he is unhappy, one quickly concludes that the person's soul is sad or sorrowful. This idea of interaction is behaviourist in its approach. Behaviourists generally believe that facts about the mental states are traceable from the physical states. This aspect of behaviourism in the Igbo understanding is in agreement with the 'reflective theory' of interaction as I suggested elsewhere. I emphasized that the mind's states reflects in the body just like one's shadow is cast in water. ${ }^{10}$ In other words, it may not be hard to find out why the bad state of mind manifests itself in the ill-being of the Igbo man the condition of the soul determines the condition of the body.

\section{IV}

From the foregoing it is necessary to show that the self is made up of two entities: the mind and body. These two entities despite their disparate nature interact based on the very underlying principle of Igbo cultural belief, the principle of causality. Nevertheless, the Igbo cultural background sees it as incomplete explaining the self just from the individual selfhood. To talk about the self in the Igbo cultural milueu entails also talking about the self as a being-for- 
others. The above therefore makes it imperative for us to view the self, briefly as a being of his community.

In the third section of this work, I briefly talked about the place of the self in the community. During the expose, I talked about the role of the blood in the very understanding of the self. The blood for the igbo man is more in depth than just a fluid that sustains the human life. For the Igbo man, the blood is a bond that unites one self to another self and this extends to the whole community. The Igbo understanding here could be likened to the Hegel's metaphysics of 'spirit'. The Igbo like Hegel believe that the 'self' cannot be explained independent of the society from common spirit that unites them all). Because of this common spirit which the Igbo people believe in and which constitute their individual community, they emphasize public virtue. For the Igbo people the life of the individual self affects the life of the society. Aja writes about this

[T]he forces have an intimate ontological relationship; preserve a bond with one another...The world of forces is held like a spider's web of which no single thread can be caused to vibrate without shaking the whole network. ${ }^{11}$

Egbeke Aja understands the self to be a force. These forces are united and are very much interactive. Every action by one force or the self has a very great effect on the whole society, thus the saying Otu mkpisi aka ruta mmanu ozuo mkpisi aka ise -when a finger is dipped into oil, it naturally spreads to the five. One self cannot exactly be conceived as an independent entity neither can the self be so subsistent that it does not require other selves to exist.

If a person in the traditional Igbo society is guilty of ' $a r u$ ' bad / ill omen, it is believed that the society will continue to suffer from such an aru until a proper communal propitiation is performed by a diviner. Evidently, the thought and the lifestyle of an individual is shaped by the entire community where in one finds oneself. It is societal beliefs that influence one's world view. Thus despite the fact that the 'self' as 'self' has an individualistic nature, it must be understood in terms of the society from where the self takes its roots. 


\section{V}

The Igbo concept of the self appears tripartite because of the difference in dialect and also because of the intrusion of the western religious system into the very culture of the Igbo people. However, our analysis shows that the Igbo concept of the self is dualistic. It appears to me that this dualistic concept of the self brings out clearly the very nature of Igbo belief system which is made manifest in their belief in causality through which the spirit -body interaction is made explainable in itself but through the society. This accounts for the Igbo people's belief in the separation of the spirit from the body thus explaining their belief in the possibility of life after death. Furthermore, this close tie which held the spirit to the body and the entire self to the community brings out the existential aspect of the self, which makes one act in the way one does and think in the way one does.

The self is not just limited to the physical as in the body No! It has the life sustaining entity the spirit which makes it possible for the self to engage in some non physical activities. The self equally may not be fully explained in the Igbo belief by just making reference to the individual self but by making reference to the environment from where an individual came. 


\section{References}

1. Ibe Nwoga Supreme God as a Stranger in Igbo religious thought (Ahiazu Mbaise: Hawk Press, 1984) P.41-43.

2. Egbeke Aja Metaphysics An Introduction (Enugu: Magnet Business Enterprise) p. 50

3. Benedict Eboh The Concept of Mkpuruobi in Igbo Worldview in E. Edeh Towards an Igbo Metaphysics (Chicago: Chicago University Press Ltd. 1985) p.74.

4. Eze Nwankwor The Theory of Igbo Immaterialism (Awka: Selcom Pub. Ltd 2004) p.14

5. Eze Nwankwor The Theory of Igbo Immaterialism (Awka: Selcom Pub. Ltd 2004) p.17

6. Bernard Williams cited by kwame Gyekye An Essay on Africa philosophical Thought: The Akan Conceptual Scheme (New York: Cambridge University Press, 1985) P. 80.

7. Nnamdi Odoemena The Dynamics of cultural revitalization: A case study of the Igbos of Nigeria (Enugu: Harris printing press ltd.1993)p. 36

8. Egbeke Aja Metaphysics An Introduction (Enugu: Magnet Business Enterprise) p. 50

9. Ibeh The Nature of Igbo Society (Awka: free Press Ltd. 1995) P. 75

10. Chuka Okoye An inquiry into the Igbo ontology in Culture And African Identity ed. by Ifeanyi Ejizu. (Delta: Cromms pub Ltd 2008) P. 101

11. Egbeke Aja Metaphysics An Introduction (Enugu: Magnet Business Enterprise) P. 51 